\title{
Declaration of the International Forum for Agroecology, Nyéléni, Mali: 27 February 2015
}

We are delegates representing diverse organizations and international movements of small-scale food producers and consumers, including peasants, indigenous peoples, communities, hunters and gatherers, family farmers, rural workers, herders and pastoralists, fisherfolk and urban people. Together, the diverse constituencies our organizations represent produce some $70 \%$ of the food consumed by humanity. They are the primary global investors in agriculture, as well as the primary providers of jobs and livelihoods in the world.

We gathered here at the Nyéléni Center in Sélingué, Mali from 24 to 27 of February 2015, to come to a common understanding of Agroecology as a key element in the construction of Food Sovereignty, and to develop joint strategies to promote Agroecology and defend it from co-optation. We are grateful to the people of Mali who have welcomed us in this beautiful land. They have taught us through their example, that the dialogue of our various forms of knowledge is based on respectful listening and on the collective construction of shared decisions. We stand in solidarity with our Malian sisters and brothers who struggle - sometimes sacrificing their lives - to defend their territories from the latest wave of land grabbing that affects so many of our countries. Agroecology means that we stand together in the circle of life, and this implies that we must also stand together in the circle of struggle against land grabbing and the criminalization of our movements.

\section{Building on the past, looking to the future}

Our peoples, constituencies, organizations and communities have already come very far in defining Food Sovereignty as a banner of joint struggle for justice, and as the larger framework for Agroecology. Our ancestral production systems have been developed over millennia, and during the past 30 to 40 years this has come to be called Agroecology. Our Agroecology includes successful practices and production, involves farmer-to-farmer and territorial processes, training schools, and we have developed sophisticated theoretical, technical and political constructions.

In 2007 many of us gathered here at Nyéléni, at the Forum for Food Sovereignty, to strengthen our alliances and to expand and deepen our understanding of Food Sovereignty, through a collective construction between our diverse constituencies. Similarly, we gather here at the Agroecology Forum 2015 to enrich Agroecology through dialogue 
between diverse food producing peoples, as well as with consumers, urban communities, women, youth, and others. Today our movements, organized globally and regionally in the International Planning Committee for Food Sovereignty (IPC), have taken a new and historic step.

Our diverse forms of smallholder food production based on Agroecology generate local knowledge, promote social justice, nurture identity and culture, and strengthen the economic viability of rural areas. As smallholders we defend our dignity when we choose to produce in an agroecological way.

\section{Overcoming multiple crises}

Agroecology is the answer to how to transform and repair our material reality in a food system and rural world that has been devastated by industrial food production and its so-called Green and Blue Revolutions. We see Agroecology as a key form of resistance to an economic system that puts profit before life.

The corporate model over-produces food that poisons us, destroys soil fertility, is responsible for the deforestation of rural areas, the contamination of water and the acidification of oceans and killing of fisheries. Essential natural resources have been commodified, and rising production costs are driving us off the land. Farmers' seeds are being stolen and sold back to us at exorbitant prices, bred as varieties that depend on costly, contaminating agrochemicals. The industrial food system is a key driver of the multiple crises of climate, food, environmental, public health and others. Free trade and corporate investment agreements, Investor-State Dispute Settlement agreements, and false solutions such as carbon markets, and the growing financialization of land and food, etc., all further aggravate these crises. Agroecology within a Food Sovereignty framework offers us a collective path forward from these crises.

\section{Agroecology at a crossroads}

The industrial food system is beginning to exhaust 164 its productive and profit potential because of its internal contradictions - such as soil degradation, herbicide-tolerant weeds, depleted fisheries, pestand disease-ravaged monocultural plantations - and its increasingly obvious negative consequences of greenhouse gas emissions, and the health crisis of malnutrition, obesity, diabetes, colon disease and cancer caused by diets heavy in industrial and junk food.

Popular pressure has caused many multilateral institutions, governments, universities and research centers, some NGOs, corporations and others, to finally recognize "Agroecology". However, they have tried to redefine it as a narrow set of technologies, to offer some tools that appear to ease the sustainability crisis of industrial food production, while the existing structures of power remain unchallenged. This co-optation of Agroecology to fine-tune the industrial food system, while paying lip service to the environmental discourse, has various names, including "climatesmart agriculture", "sustainable-" or "ecologicalintensification", industrial monoculture production of "organic" food, etc. For us, these are not Agroecology: we reject them, and we will fight to expose and block this insidious appropriation of Agroecology.

The real solutions to the crises of the climate, malnutrition, etc., will not come from conforming to the industrial model. We must transform it and build our own local food systems that create new rural-urban links, based on truly agroecological food production by peasants, artisanal fishers, pastoralists, indigenous peoples, urban farmers, etc. We cannot allow Agroecology to be a tool of the industrial food production model: we see it as the essential alternative to that model, and as the means of transforming how we produce and consume food into something better for humanity and our Mother Earth.

\section{Our common pillars and principles of agroecology}

Agroecology is a way of life and the language of Nature that we learn as her children. It is not a mere set of technologies or production practices. 


\section{The Nyéléni Declaration}

It cannot be implemented the same way in all territories. Rather it is based on principles that, while they may be similar across the diversity of our territories, can and are practiced in many different ways, with each sector contributing their own colors of their local reality and culture, while always respecting Mother Earth and our common, shared values.

The production practices of Agroecology (such as intercropping, traditional fishing and mobile pastoralism, integrating crops, trees, livestock and fish, manuring, compost, local seeds and animal breeds, etc.) are based on ecological principles like building life in the soil, recycling nutrients, the dynamic management of biodiversity and energy conservation at all scales. Agroecology drastically reduces our use of externally-purchased inputs that must be bought from industry. There is no use of agrotoxins, artificial hormones, GMOs or other dangerous new technologies in Agroecology.

Territories are a fundamental pillar of Agroecology. Peoples and communities have the right to maintain their own spiritual and material relationships to their lands. They are entitled to secure, develop, control, and reconstruct their customary social structures and to administer their lands and territories, including fishing grounds, both politically and socially. This implies the full recognition of their laws, traditions, customs, tenure systems, and institutions, and constitutes the recognition of the self-determination and autonomy of peoples.

Collective rights and access to the Commons are fundamental pillars of Agroecology. We share access to territories that are the home to many different peer groups, and we have sophisticated customary systems for regulating access and avoiding conflicts that we want to preserve and to strengthen.

The diverse knowledge and ways of knowing of our peoples are fundamental to Agroecology. We develop our ways of knowing through dialogue among them (diálogo de saberes). Our learning processes are horizontal and peer-to-peer, based on popular education. They take place in our own training centers and territories (farmers teach farmers, fishers teach fishers, etc.), and are also intergenerational, with exchange of knowledge between youth and elders. Agroecology is developed through our own innovation, research, and crop and livestock selection and breeding.

The core of our cosmovisions is the necessary equilibrium between nature, the cosmos and human beings. We recognize that as humans we are but a part of nature and the cosmos. We share a spiritual connection with our lands and with the web of life. We love our lands and our peoples, and without that, we cannot defend our Agroecology, fight for our rights, or feed the world. We reject the commodification of all forms of life.

Families, communities, collectives, organizations and movements are the fertile soil in which Agroecology flourishes. Collective self-organization and action are what make it possible to scale-up Agroecology, build local food systems, and challenge corporate control of our food system. Solidarity between peoples, between rural and urban populations, is a critical ingredient.

The autonomy of Agroecology displaces the control of global markets and generates self-governance by communities. It means we minimize the use of purchased inputs that come from outside. It requires the re-shaping of markets so that they are based on the principles of solidarity economy and the ethics of responsible production and consumption. It promotes direct and fair short distribution chains. It implies a transparent relationship between producers and consumers, and is based on the solidarity of shared risks and benefits.

Agroecology is political; it requires us to challenge and transform structures of power in society. We need to put the control of seeds, biodiversity, land and territories, waters, knowledge, culture and the commons in the hands of the peoples who feed the world.

Women and their knowledge, values, vision and leadership are critical for moving forward. Migration 
and globalization mean that women's work is increasing, yet women have far less access to resources than men. All too often, their work is neither recognized nor valued. For Agroecology to achieve its full potential, there must be equal distribution of power, tasks, decision-making and remuneration.

Youth, together with women, provide one of the two principal social bases for the evolution of Agroecology. Agroecology can provide a radical space for young people to contribute to the social and ecological transformation that is underway in many of our societies. Youth bear the responsibility for carrying forward the collective knowledge learned from their parents, elders and ancestors into the future. They are the stewards of Agroecology for future generations. Agroecology must create a territorial and social dynamic that creates opportunities for rural youth and values women's leadership.

\section{STRATEGIES}

We are building, defending and strengthening Agroecology together with others. Our evolving strategies include:

\section{Promotion of agroecological production through policies that...}

1. Are territorial and holistic in their approach to social, economic and natural resources issues.

2. Secure access to land and resources in order to encourage long-term investment by smallscale food producers.

3. Ensure an inclusive and accountable approach to the stewardship of resources, food production, public procurement policies, urban and rural infrastructure, and urban planning.

4. Promote truly democratized planning processes in conjunction with relevant local governments and authorities.

5. Promote appropriate health and sanitation regulations that do not discriminate against small-scale food producers and processors who practice Agroecology.

6. Promote policy to integrate the health and nutrition aspects of Agroecology and of traditional medicines.
7. Ensure pastoralists' access to and control over pastures, migration routes and sources of water as well as mobile services such as health, education and veterinary services that are based on and compatible with traditional practice.

8. Ensure customary rights to the Commons. Ensure seed policies that guarantee the collective rights of peasants' to use, exchange, breed, select and sell their own seeds.

9. Attract and support young people to join agroecological food production through strengthening access to land and natural resources, ensuring fair income, knowledge exchange and transmission.

10. Support urban and peri-urban agroecological production.

11. Protect the rights of communities that practice wild capture, hunting and gathering in their traditional areas - and encourage the ecological and cultural restoration of territories to their former abundance.

12. Implement policies that ensure the rights of fishing communities.

13. Implement the Voluntary Guidelines on the Tenure of Land, Fisheries and Forests of the Committee on World Food Security and the Voluntary Guidelines on Securing Smallscale Fisheries of the FAO.

14. Develop and implement policies and programs that guarantee the right to a dignified life for rural workers, including true agrarian reform, and Agroecology training.

\section{Knowledge sharing}

1. Horizontal exchanges (peasant-to-peasant, fisher-to-fisher, pastoralist-to-pastoralist, consumer-and-producer, etc.) and intergenerational exchanges between generations and across different traditions, including new ideas. Women and youth must be prioritised.

2. Peoples' control of the research agenda, objectives and methodology.

3. Systemize experience to learn from and build on historical memory. 


\section{The Nyéléni Declaration}

\section{Recognition of the central role of women}

1. Fight for equal women's' rights in every sphere of Agroecology, including workers' and labour rights, access to the Commons, direct access to markets, and control of income.

2. Programs and projects must fully include women at all stages, from the earliest formulation through planning and application, with decision-making roles.

\section{Build local economies}

1. Promote local markets for local products.

2. Support the development of alternative financial infrastructure, institutions and mechanisms to support both producers and consumers.

3. Reshape food markets through new relationships of solidarity between producers and consumers.

4. Develop links with the experience of solidarity economy and participatory guarantee systems, when appropriate.

\section{Further develop and disseminate our vision of Agroecology}

1. Develop a communications plan for our vision of Agroecology

2. Promote the health care and nutritional aspects of Agroecology

3. Promote the territorial approach of Agroecology

4. Promote practices that allows youth to carry forward the permanent regeneration of our agroecological vision

5. Promote Agroecology as a key tool to reduce food waste and loss across the food system

\section{Build alliances}

1. Consolidate and strengthen existing alliances such as with the International Planning Committee for Food Sovereignty (IPC)

2. Expand our alliance to other social movements and public research organizations and institutions

\section{Protect biodiversity and genetic resources}

1. Protect, respect and ensure the stewardship of biodiversity
2. Take back control of seeds and reproductive material and implement producers' rights to use, sell and exchange their own seeds and animal breeds

3. Ensure that fishing communities play the most central role in controlling marine and inland waterways

\section{Cool the planet and adapt to climate change}

1. Ensure international institutions and governments recognize Agroecology as defined in this document as a primary solution for tackling and adapting to climate change, and not "climate-smart agriculture" or other false versions of Agroecology

2. Identify, document and share good experiences of local initiatives on Agroecology that address climate change.

3. Denounce and fight corporate and institutional capture of Agroecology

4. Fight corporate and institutional attempts to grab Agroecology as a means to promote GMOs and other false solutions and dangerous new technologies.

5. Expose the corporate vested interests behind technical fixes such as climate-smart agriculture, sustainable intensification and "finetuning" of industrial aquaculture.

6. Fight the commodification and financialization of the ecological benefits of Agroecology.

\section{Denounce and fight corporate and insti- tutional capture of Agroecology}

1. Fight corporate and institutional attempts to grab Agroecology as a means to promote GMOs and other false solutions and dangerous new technologies.

2. Expose the corporate vested interests behind technical fixes such as climate-smart agriculture, sustainable intensification and "fine-tuning" of industrial aquaculture.

3. Fight the commodification and financialization of the ecological benefits of Agroecology.

We have built Agroecology through many initiatives and struggles. We have the legitimacy to lead it into the future. Policy makers cannot move 


\section{Development 58(2-3): Upfront}

forward on Agroecology without us. They must respect and support our agroecological processes rather than continuing to support the forces that destroy us. We call on our fellow peoples to join us in the collective task of collectively constructing Agroecology as part of our popular struggles to build a better world, a world based on mutual respect, social justice, equity, solidarity and harmony with our Mother Earth.

The International Forum on Agroecology was organized at the Nyeleni Center in Mali, from
24 to 27 February 2015 by the following organisations: Coordination Nationale des Organisations Paysannes du Mali (CNOP Mali) as chair; La Via Campesina (LVC), Movimiento Agroecológico de América Latina y el Caribe (MAELA), Réseau des organisations paysannes et de producteurs de l'Afrique de l'Ouest (ROPPA), World Forum of Fish Harvesters and Fishworkers (WFF), World Forum of Fisher Peoples (WFFP), World Alliance of Mobile Indigenous Peoples (WAMIP), More and Better $(\mathrm{M} a \mathrm{~B})$ 